\title{
Using Monoclonal Antibody to Determine Lead Ions with a Localized Surface Plasmon Resonance Fiber-optic Biosensor
}

\author{
Tsao-Jen Lin * and Mon-Fu Chung \\ Department of Chemical Engineering, National Chung-Cheng University, Chia-Yi 621, Taiwan
}

* Author to whom correspondence should be addressed. E-mail: chmtjl@ccu.edu.tw;

Tel: $886-5-272044$ ext 33405

Received: 4 October 2007 / Accepted: 24 January 2008 / Published: 25 January 2008

\begin{abstract}
A novel reflection-based localized surface plasmon resonance (LSPR) fiberoptic probe has been developed to determine the heavy metal lead ion concentration. Monoclonal antibody as the detecting probe containing massive amino groups to capture $\mathrm{Pb}(\mathrm{II})$-chelate complexes was immobilized onto gold nanoparticle-modified optical fiber (NMAuOF). The optimal immobilizing conditions of monoclonal antibody on to the NMAuOF are $189 \mu \mathrm{g} / \mathrm{mL}$ in $\mathrm{pH} 7.4 \mathrm{PBS}$ for $2 \mathrm{~h}$ at $25^{\circ} \mathrm{C}$. The absorbability of the functionalized NMAuOF sensor increases to $12.2 \%$ upon changing the $\mathrm{Pb}$ (II)-EDTA level from 10 to $100 \mathrm{ppb}$ with a detection limit of $0.27 \mathrm{ppb}$. The sensor retains $92.7 \%$ of its original activity and gives reproducible results after storage in 5\% D-(+)-Trehalose dehydrate solution at $4{ }^{\circ} \mathrm{C}$ for 35 days. In conclusion, the monoclonal antibodyfunctionalized NMAuOF sensor shows a promising result for determining the concentration of $\mathrm{Pb}(\mathrm{II})$ with high sensitivity.
\end{abstract}

Keywords: localized surface plasmon resonance, biosensor, gold nanoparticle, monoclonal antibody, lead-chelate complex.

\section{Introduction}

Lead is one of the most widely used heavy metals and has a large number of industrial applications, including battery manufacture, paint, gasoline, alloys, radiation shielding, tank lining and piping. Among these, lead in paint and gasoline together accounts for most of the lead now in the environment and leads to serious pollution and human health problems. Elevated levels of lead can be harmful if 
levels are built up in the body. Over the past several decades, it is found that lead is toxic by ingestion and inhalation, can affect the gut and central nervous system, and can cause anemia [1,2]. Besides, lead overexposure can also cause birth defects, mental retardation, behavioral disorders, and death in fetuses and young children $[3,4]$. Hence, detection and quantization of lead contamination is an important issue with the increasing requirement of environmental concern and health safety.

Traditionally, the commonly used methods for determination of lead are atomic absorption (AA) spectroscopy [5] and inductively coupled plasma (ICP) optical emission spectrometry, and inductively coupled plasma mass spectrometry (ICPMS) [6,7]. These methods are sensitive and allow discrimination among different metal ions but require a tedious sample pretreatment and sophisticated instrument. Therefore, it is essential to develop a rapid and sensitive screening method to ascertain the presence of lead for in situ environmental monitoring. In the past, a lot of efforts have been devoted to develop rather inexpensive biosensors by using enzyme, peptide, protein, or antibody as recognition elements for the detection of heavy metals [8-12]. Theses recognition elements may be immobilized on a suitable surface or supporter, and its binding or inhibition can be measured by different detection techniques such as ion-sensitive field effect transistors, potentiometric and piezoelectric devices, amperometric electrodes, and optical-based biosensors. Among the recognition elements, monoclonal antibody provides a unique opportunity for distinguishing different metals and a basis for rapid and sensitive immunoassays [13-15]. To increase association with monoclonal antibody, small metal ions were initially conjugated with chelators to form a metal-chelate complex. The metal-chelate complexes represent a distinct class of hapten ligands which was recognized by specific amino acid residues in the antibody's binding-sites to comprise a special subset of metal-binding protein [16,17]. Therefore, the specific binding characteristics of monoclonal antibody will be employed to our new design of biosensor for lead detection.

A novel fiber-based biosensor with extraordinary optic properties of gold nanoparticles $\left(\mathrm{NM}_{\mathrm{Au}}\right)$ has recently been explored [18,19]. The absorption band of gold nanoparticles is obtained when the incident photon frequency is resonant with the collective oscillation of the conduction electrons and is known as the localized surface plasmon resonance (LSPR). The resonance frequency of the LSPR is highly dependent upon the local environment of the nanoparticles [20-22]. Therefore, the optical properties (e.g., absorbance and peak wavelength) of gold nanoparticles are sensitive to the refractive index of the surrounding solvent and the binding events to those functionalized nanoparticles. With a suitable receptor immobilized at the surface of the gold nanoparticles, the resulting LSPR fiber-optic sensor can detect the corresponding analyte even if the analyte is spectroscopically silent in the UV-vis region. Hence, the presence of analytes can be determined directly without the use of labeled molecules.

For this study, a monoclonal antibody-functionalized fiber-based biosensor utilizing the LSPR effect was developed to evaluate the concentration of $\mathrm{Pb}(\mathrm{II})$. By using a self-assembling technique, a bioactive layer consisting of the monoclonal antibody was immobilized by covalent coupling onto the gold nanoparticle layer and the optimal conditions of immobilization will be examined. Prior to detecting, $\mathrm{Pb}$ (II) was treated with excess chelators (i.e., EDTA) to form $\mathrm{Pb}$ (II)-chelate complexes. The monoclonal antibody can exclusively bind with $\mathrm{Pb}(\mathrm{II})$-chelate complex and causes a change in light attenuation. Based on the correlation between binding rate and light attenuation, the concentration of 
$\mathrm{Pb}$ (II) can be determined. Several factors, including stability and binding constant, were investigated as well.

\section{Materials and Methods}

\subsection{Reagents and Materials}

Monoclonal Antibody to lead (K55061M) was purchased from Biodesign International Company, USA. Basically, Pb(II)-EDTA was covalently conjugated to keyhole limpet hemocyanin (KLH) and was used as an immunogen. Then, the $\mathrm{KLH}-\mathrm{Pb}(\mathrm{II})$ conjugate was injected into mouse to produce the monoclonal antibody. Multimode plastic-clad silica optical fiber (model F-MBC) was purchased from Newport (Irvine, CA) with core and cladding diameters of 400 and $430 \mu \mathrm{m}$, respectively. The following chemicals, n-hexadecyltrimethylammonium bromide (CTAB, Fluka), sodium borohydride (Lancaster), 3-(mercaptopropyl)-trimethoxysilane (MPTMS, Acros), cystamine dihydrochloride (Sigma), phosphate buffered saline (PBS, Sigma), N-(3-Dimethylaminopropy)-N-ethylcarbodiimide hydrochloride (EDC, Sigma), N-hydroxy- succinimide (NHS, Sigma), ethylenediamine tetraacetic acid (EDTA, Sigma), lead(II) nitrate (Osaka, 99+\%), D-(+)-Trehalose dehydrate (Sigma), were used as received. All aqueous solutions were prepared with water purified using a YMDI-100 water purification unit (Yeameei Membrane) with a specific resistance of $18 \mathrm{M} \Omega \mathrm{cm}$.

\subsection{Preparation of gold nanoparticle-modified optical fiber}

First, colloidal $\mathrm{Au}$ solution was prepared by mixing hydrogen tetracholoraurate $(1.78 \mathrm{~mL}, 25.4$ $\mathrm{nM}), 8.22 \mathrm{~mL}$ of chloroform, and $0.4 \mathrm{~mL}$ of a $0.02 \mathrm{M}$ ethanol solution of CTAB for $10 \mathrm{~min}$ to form a $4.52 \times 10^{-4} \mathrm{M}$ hydrogen tetrachloroaurate solution. Freshly prepared $\mathrm{NaBH}_{4}$ ethanol solution $(0.8 \mathrm{~mL}$, $0.15 \mathrm{M}$ ) was added to the hydrogen tetrachloroaurate solution with vigorous stirring for $30 \mathrm{~min}$. Then, the unclad portion $(5 \mathrm{~cm})$ of the optical fibers was cleaned for $30 \mathrm{~min}$ in a bath consisting of 3 volumes of $30 \% \mathrm{H}_{2} \mathrm{O}_{2}$ and 7 volumes of concentrated $\mathrm{H}_{2} \mathrm{SO}_{4}$. The clean unclad portions of the optical fibers were then submerged into vials of 1\% solution of MPTMS in toluene. After $8 \mathrm{~h}$, the optical fibers were rinsed with methanol to remove unbound monomers from the surface. After thorough rinsing, the unclad portions of the optical fibers were immersed in Au solution for $5 \mathrm{~h}$ to form a self-assembled gold nanoparticle monolayer $\left(\mathrm{NM}_{\mathrm{Au}}\right)$ on the core surface. Subsequently, the modified optical fibers were rinsed sequentially with water, methanol, and chloroform. Figs. 1(a) and 1(b) were shown the 2D and 3-D AFM images of surfaces on the prepared MPTMS and gold nanoparticle-modified optical fiber, respectively. From the images of Fig. 1(a), the surface modified by MPTMS became smoother with a $2.05 \mathrm{~nm}$ roughness. A Joel transmission electron microscopic (TEM) 1200EX was applied to observe the samples, which had been dispersed and allowed to dry on copper grids. Histograms derived from TEM image analysis showed that the mean diameter of $\mathrm{Au}$ nanoparticles was 9.6 \pm 2.3 nm, as shown in Fig. 1(b). 

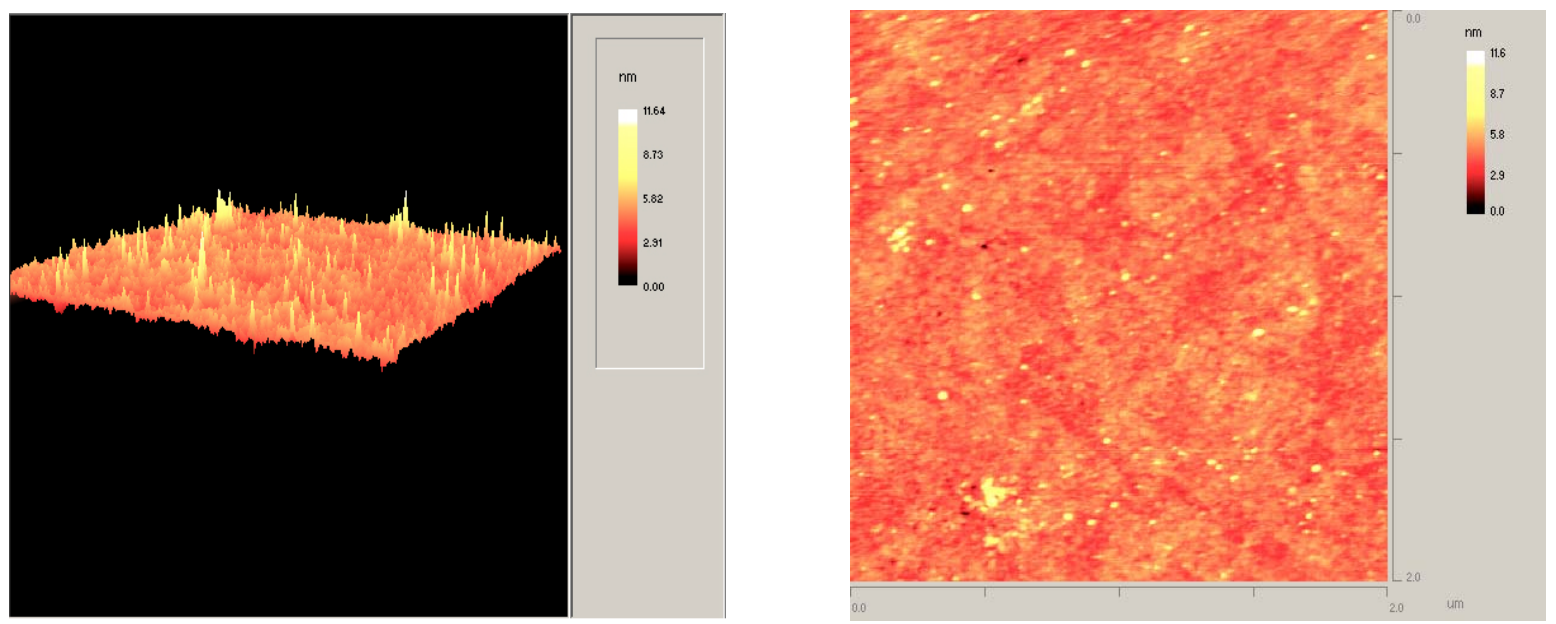

(a)
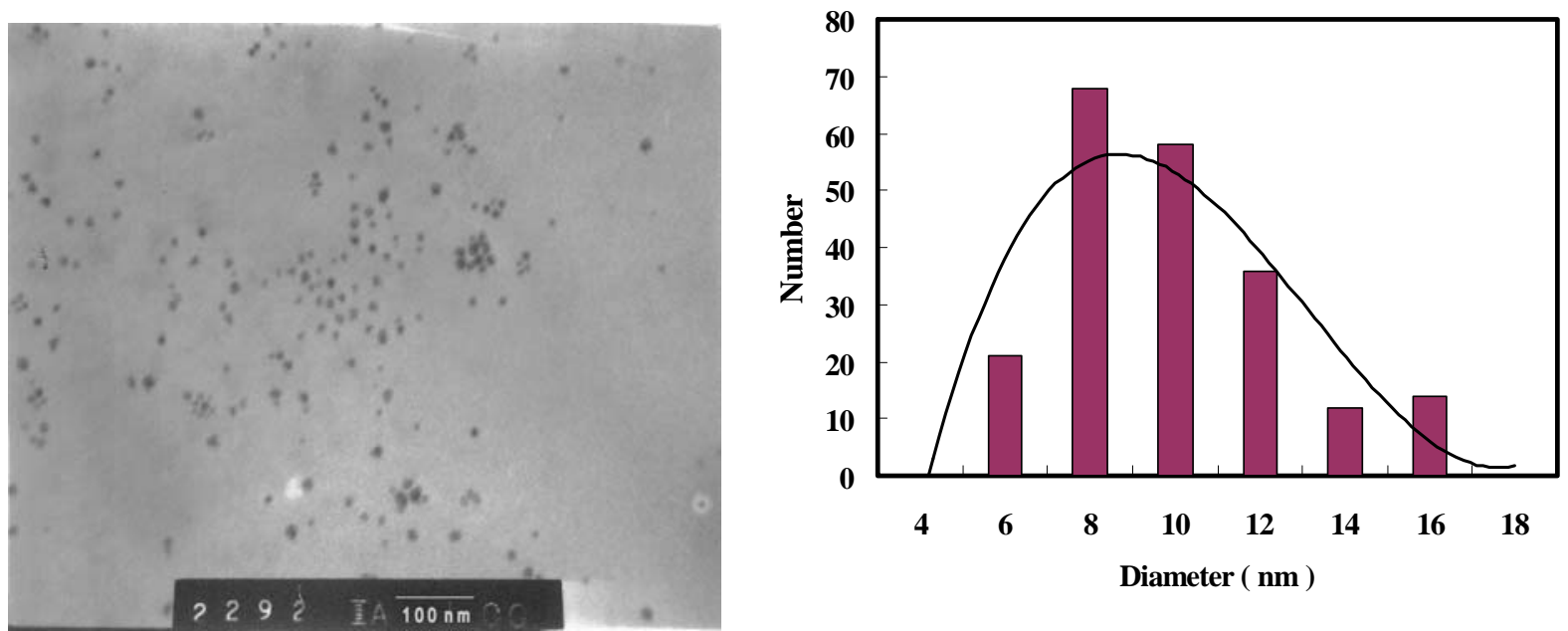

(b)

Figure 1. (a) Images of 2-D and 3-D AFM surfaces on the prepared MPTMS; (b) Electron micrograph and particle size distribution of pure Au nanoparticles.

\subsection{Immobilization of antibody onto $N M_{A u}$}

$\mathrm{NM}_{\mathrm{Au}}$ was initially modified to form a self-assembled monolayer (SAM) of cystamine by immersing $\mathrm{NM}_{\mathrm{Au}}$ in $0.02 \mathrm{M}$ cystamine dihydrochloride (pH 7.4 in PBS) for $2 \mathrm{~h}$ to form an amine functional group. The cystamine-modified $\mathrm{NM}_{\mathrm{Au}}$ was further immersed in a PBS solution with containing $450 \mathrm{mM}$ EDC, $90 \mathrm{mM}$ NHS, and various concentrations of antibody for $2 \mathrm{~h}$ at room temperature, rinsed with PBS, and air-dried at room temperature. Then, the amine group of cystamine modified on the $\mathrm{NM}_{\mathrm{Au}}$ can couple with the activated succinimide esters reacting from antibody and NHS, and finally form an amino bond between cystamine and antibody, as shown in Fig. 2. The concentration of antibody, $\mathrm{pH}$ value of solution, and incubation time were varied to find the optimal immobilization conditions. 


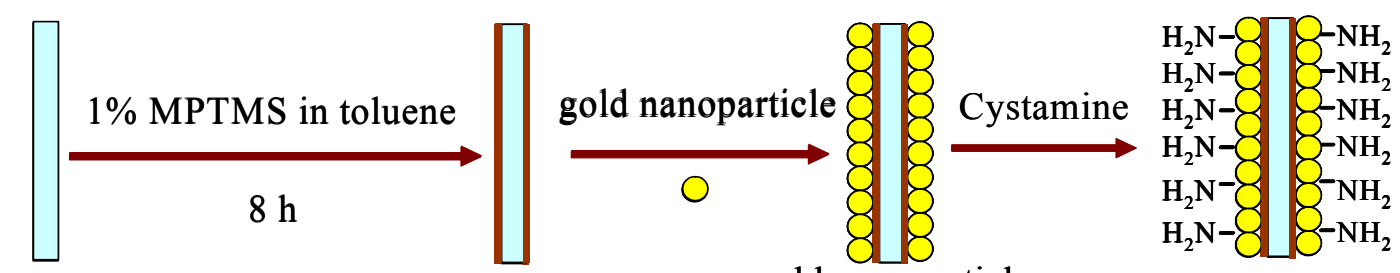

optical fiber

gold nanoparticle

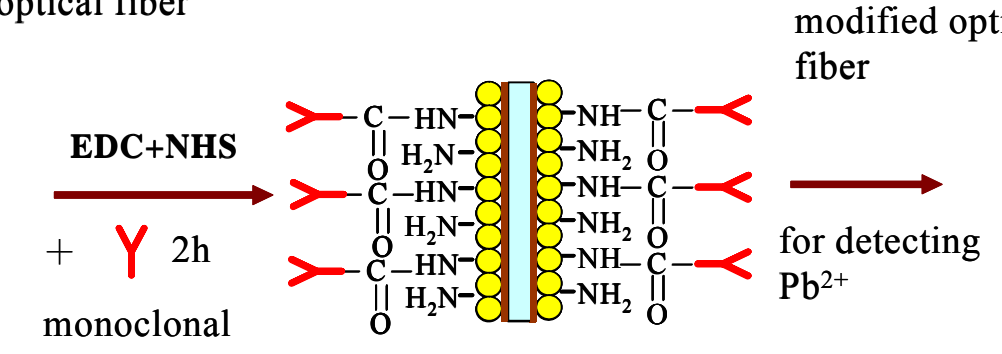
antibody

Figure 2. The chemical reactions scheme carried out for covalent binding of monoclonal antibody to the fiber-based LSPR sensor.

\subsection{Pb(II) and other metals detection by antibody modified sensors}

In LSPR sensors, the light attenuation will be affected as the analyte molecules are captured or reacted by a molecular recognition element immobilized on the sensor surface. When $\mathrm{Pb}$ (II) was given with an excess of EDTA, all $\mathrm{Pb}$ ions were bound in a 1:1 $\mathrm{Pb}$ (II)-EDTA complex. It is because of the high binding affinity of EDTA to insure that all the $\mathrm{Pb}(\mathrm{II})$ in the sample form a complex with EDTA. Besides, the antibody exhibited little or no ability to bind to the metal-free EDTA. In this study, the reaction was carried out in standard solution as mentioned in Eq. (1). When $\mathrm{Pb}(\mathrm{II})$-EDTA complex binds with antibody, the decreasing light intensity is correlated to the concentration of $\mathrm{Pb}(\mathrm{II})$. The degree of absorbability can be calculated according to the following formula:

$$
\text { Absorbabilty }(\%)=\frac{I_{0}-I_{1}}{I_{0}} \times 100
$$

where $I_{0}$ and $I_{1}$ are the averaged light intensity measured at the initial antibody activity without and with $\mathrm{Pb}$ (II)-EDTA complex, respectively. According to World Health Organization (WHO), the $\mathrm{Pb}$ (II) concentration in drinking-water should be less than $50 \mathrm{ppb}$. In this study, the detecting range of $\mathrm{Pb}(\mathrm{II})$ is chosen from 10 to $100 \mathrm{ppb}$ in $\mathrm{pH} 7.4 \mathrm{PBS}$ buffer solution. For comparison, other metals, including $\mathrm{Cu}(\mathrm{II}), \mathrm{Ni}(\mathrm{II})$, and $\mathrm{Mg}(\mathrm{II})$, had performed the same treatments and testing as $\mathrm{Pb}(\mathrm{II})$.

\subsection{Stability of antibody modified sensors}

For evaluate the stability, the immobilized LSPR sensors were immersed in a 5\% D-(+)-Trehalose dehydrate solution and were stored in a $4{ }^{\circ} \mathrm{C}$ refrigerator. The preserved sensors were taken out for the 
change of calibration curve on $\mathrm{Pb}(\mathrm{II})$-EDTA complex detection after 1, 7, 14, 21, 28, and 35 days. The relative activity for each time of test can be calculated by the following formula:

$$
\text { relative activity }(\%)=\frac{A_{o}-A_{n}}{A_{o}} \times 100
$$

Where $A_{o}$ and $A_{n}$ were the change absorbabilities of the sensor on the initial manufactured day and the preserved $\mathrm{n}$ days, respectively.

\subsection{Instrumentation and measurements}

The optical configuration for the gold nanoparticle-modified optical fiber biosensor is a reflectionbased fiber-optic configuration, as shown in Fig. 3. The system consists of a laser (Hitachi HL6320G laser diode, $635 \mathrm{~nm}, 10 \mathrm{~mW}$; Thorlabs LDC500 laser diode controller; Thorlabs TEC2000 temperature controller; Thorlabs TCLDM9 laser mount), a chopper (Stanford Research SR540), a fiber coupler, a beam splitter, a sensing fiber, a liquid cell $(10 \mathrm{~mL})$, a photo-receiver (Thorlabs PDA55), and a lock-in amplifier (Stanford Research SR830). For the detail description of the biosensor system, please refer to Chau et al. (2006) [19]. The temperature of the liquid testing cell was maintained by a circulatory waterbath (Wisdom, model LC-06) within $\pm 0.05 \mathrm{~K}$. The Pb(II)-EDTA complex solution was filled in the liquid testing cell, in which the LSPR sensor was installed horizontally. After reaching a balance, a new stable response can be attained in $5 \mathrm{~min}$. However, to make sure reaction reaching to equilibrium state, the responding signals are taken over 10 minutes after addition of the $\mathrm{Pb}(\mathrm{II})$-EDTA complex solution. In this work, at least three replicates were performed for each parameter.

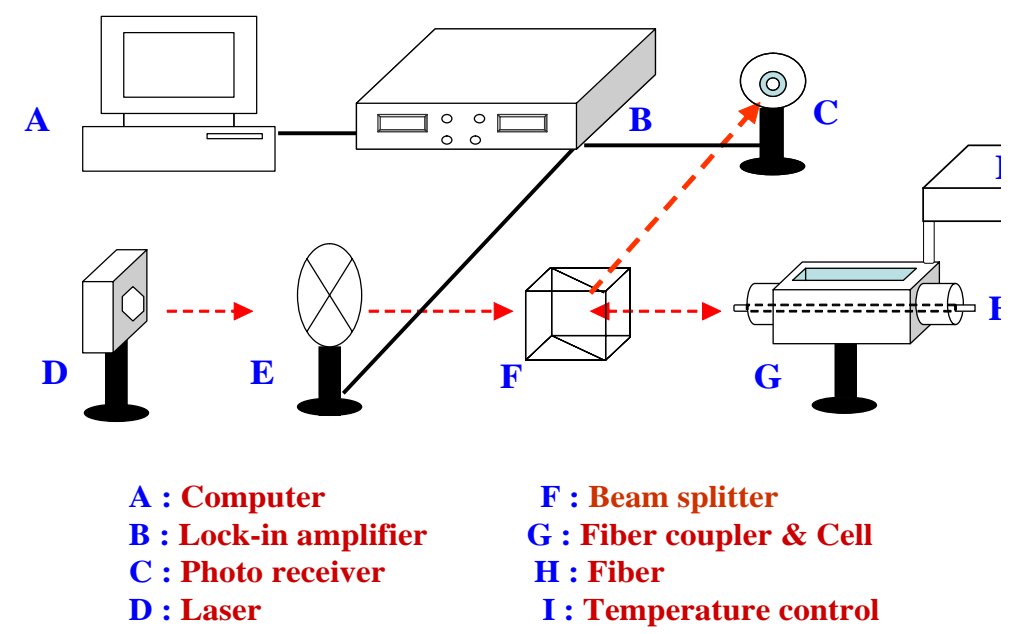

Figure 3. The schematic representation of the LSPR biosensor system.

\section{Results and Discussion}

\subsection{Comparing probe w/wt immobilizing monoclonal antibody on $N M_{A u}$}

While applying the LSPR sensor, the capture of $\mathrm{Pb}(\mathrm{II})$-EDTA complex by the immobilized antibody causes a decrease of light intensity at the detector due to an increase in the local RI. Fig. 4 shows an example of serial responding signals from the antibody modified LSPR sensor immersing in a pH 7.4 PBS buffer solution after sequential addition of $\mathrm{Pb}(\mathrm{II})$-EDTA complex to final concentrations 
of $100 \mathrm{ppb}$. The responding signals decrease with increasing $\mathrm{Pb}$ (II)-EDTA complex concentration at room temperature and with a good linearity (which will be shown later). Notably, under the same operating conditions, there is no significant responding change for the fiber without immobilizing antibody, suggesting that the antibody can substantially differentiate the change of $\mathrm{Pb}(\mathrm{II})$-EDTA complex at low concentrations.

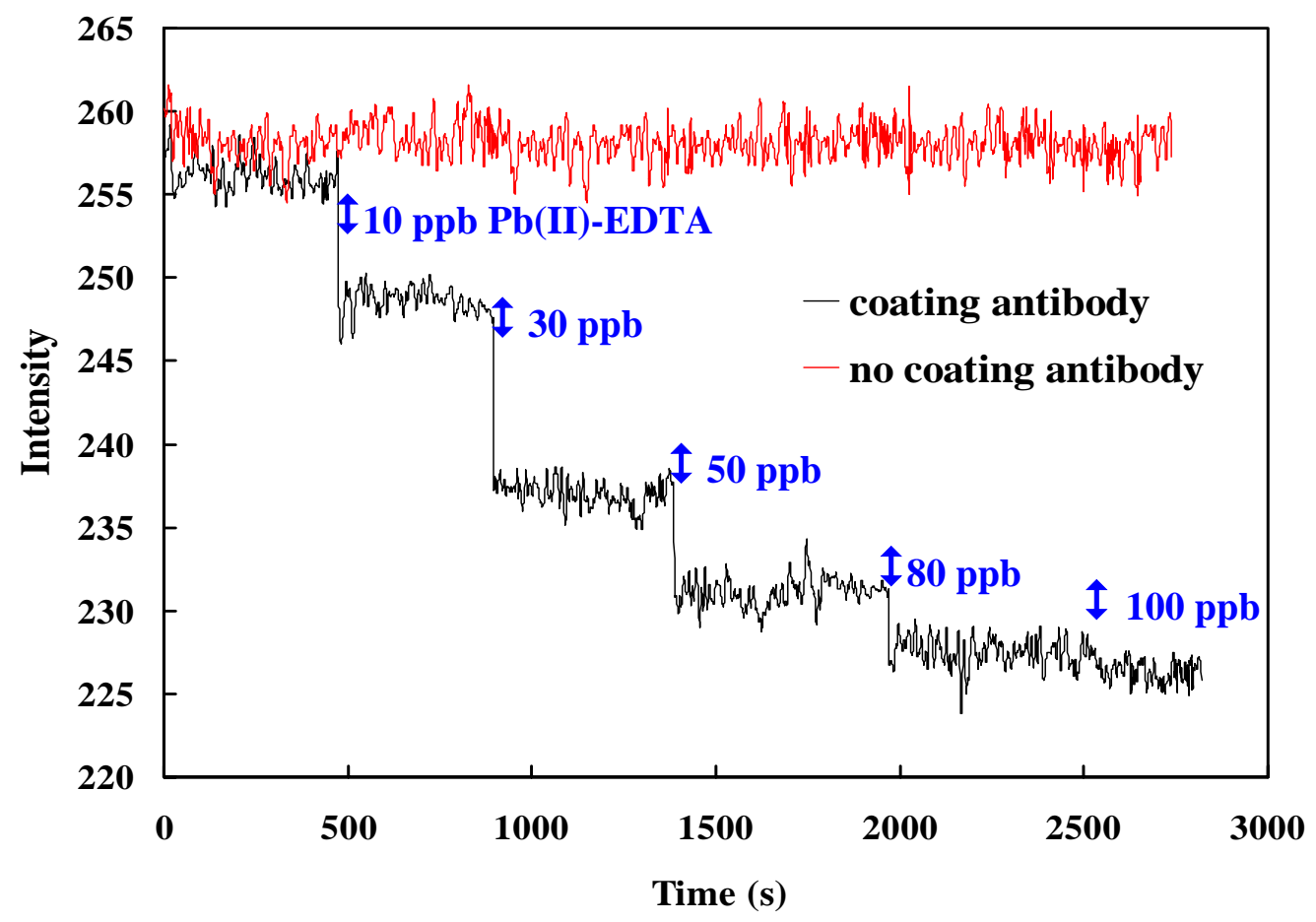

Figure 4. An example of serial $\mathrm{Pb}$ (II)-EDTA complex response signal in the range of $10 \sim 100 \mathrm{ppb}$ by two sensors with/without monoclonal antibody coating.

\subsection{Optimal monoclonal antibody immobilizing conditions}

The sensitivity of an optic-fiber sensor is related to the immobilizing conditions, such as the amount of immobilized ligand and $\mathrm{pH}$ value of the solution [23]. The amount of immobilized ligand is determined by the ligand concentration and incubation period. Fig. 5 shows the effects of the antibody concentration, and incubation time and $\mathrm{pH}$ on the response signals for $\mathrm{Pb}(\mathrm{II})$-EDTA complex, respectively. In theory, higher incubating antibody concentration (or the longer the incubating time) revealed larger immobilization of monoclonal antibody onto the fiber, resulting in a stronger LSPR effect and a smaller $\mathrm{I}_{0}$. Besides, under a constant concentration of $\mathrm{Pb}$ (II)-EDTA complex the sensor immobilized with more antibody has the higher residua to react $\mathrm{Pb}$ (II)-EDTA complex with a smaller $I_{1}$, results in a higher absorbability and resolution with a rather good linearity. From Fig. 5(a) and (b), it can be seen that as the incubating antibody concentration and time increases from $94.5 \mu \mathrm{g} / \mathrm{mL}$ and 1 $\mathrm{h}$, respectively, to $189 \mu \mathrm{g} / \mathrm{mL}$ and $2 \mathrm{~h}$, the absorbability reaches a maximal value of $12.2 \%$ with a good linearity $\left(\mathrm{R}^{2}=0.994\right)$ for $\mathrm{Pb}(\mathrm{II})$-EDTA complex concentration ranging from 10 to $100 \mathrm{ppb}$. However, upon further increase in the incubating enzyme concentration or time, the amount of immobilized antibody onto the fiber becomes over saturated and causes steric hindrance from binding with $\mathrm{Pb}(\mathrm{II})$-EDTA complex, leading to a less response in absorbability 
(a)

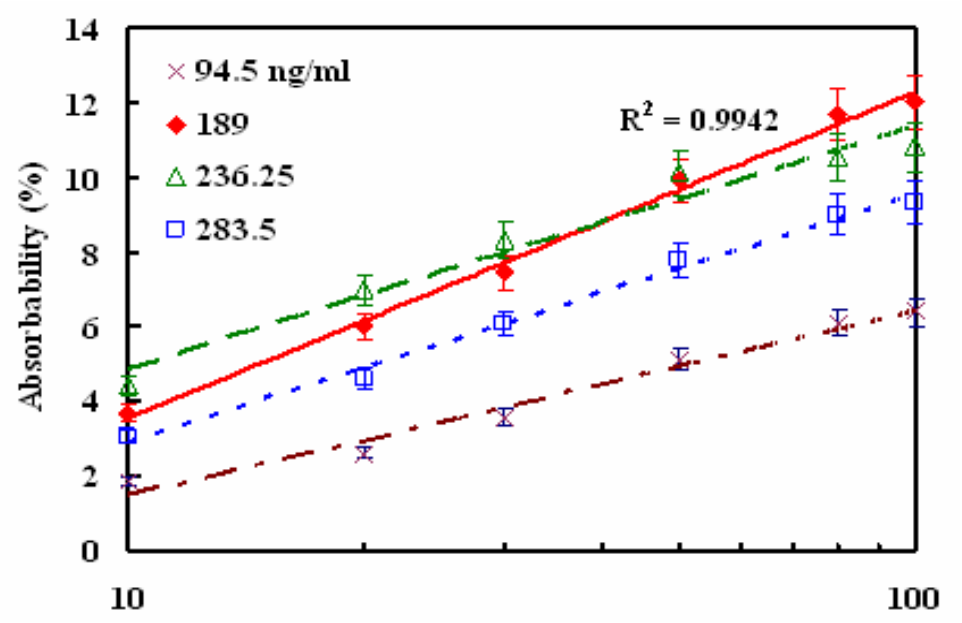

(b)

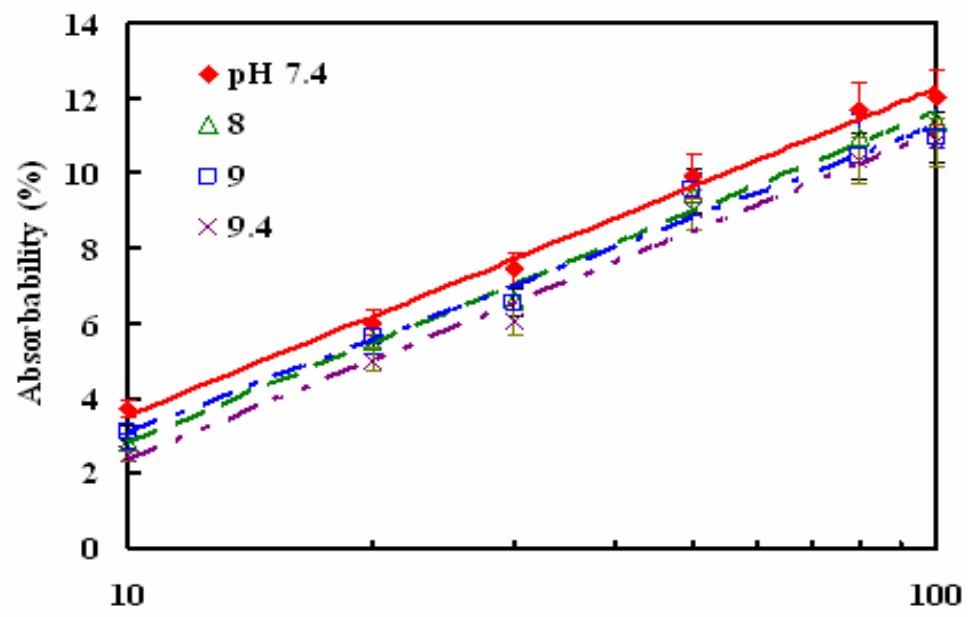

(c)

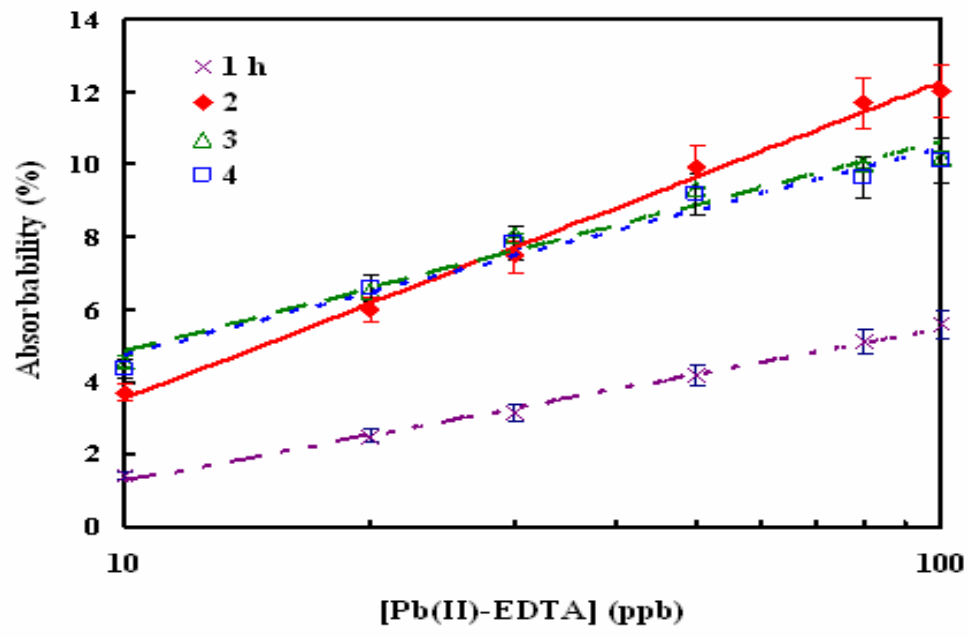

Figure 5. Effects of (a) the incubating monoclonal antibody concentration, (b) incubating time, and (c) $\mathrm{pH}$ on the response for detecting 10 100 ppb $\mathrm{Pb}$ (II)-EDTA complex in $\mathrm{pH}$ 7.4 PBS buffer solution at $25^{\circ} \mathrm{C}$.

Figure 5(c) shows the plots of the absorbability versus $\mathrm{Pb}$ (II)-EDTA complex concentration with different sensors incubated in various $\mathrm{pH}$ values of $189 \mu \mathrm{g} / \mathrm{mL}$ antibody solution for $2 \mathrm{~h}$. In the lower $\mathrm{pH}$, the coupling between succinimide esters formed by antibody and NHS and amine group on 
cystamine is less effective to form the amino covalent binding [24]. Hence, only the base conditions of incubation will be considered in the study. From Fig. 5(c), it shows that the maximal absorbability change is found at $\mathrm{pH} 7.4$, after which the absorbability decreases again. This result can be attributed to two reasons: first, the protein denaturation of antibody in the higher $\mathrm{pH}$ condition may lead to its lower activity. Second, the charge of antibody becomes negative in the higher $\mathrm{pH}$ condition, which leads to over saturated immobilizing antibody onto the fiber. In summary, the optimal immobilization conditions for modifying the LSPR sensor are $189 \mu \mathrm{g} / \mathrm{mL}$ antibody and $\mathrm{pH} 7.4$ for $2 \mathrm{~h}$ incubation, and will be applied for the rest of the studies. With the limit of detection (LOD) defined as the intensity at a $\mathrm{Pb}(\mathrm{II})$-EDTA complex concentration that yields a signal-to-noise $(\mathrm{S} / \mathrm{N})$ ratio of 3 , the LOD of the sensor with optimal immobilization is $0.27 \mathrm{ppb}$.

\subsection{Temperature effect and comparison with other metal ions}

Monoclonal antibody is a protein, of which activity depends on temperature. The antibody's binding and dissociation capabilities with metal-chelate complex are strongly affected by temperature. Fig. 6 shows the response of absorbability for detecting 10 100 ppb $\mathrm{Pb}$ (II)-EDTA complex under different detecting temperatures. The optimal detecting temperature for antibody responding to $\mathrm{Pb}$ (II)EDTA complex is at $25^{\circ} \mathrm{C}$, after that the change of absorbability becomes less. An increasing temperature may enhance both the binding and dissociation rate. However, based on above results, it can be inferred that the temperature effects on the dissociation rate between antibody and $\mathrm{Pb}$ (II)EDTA complex is larger than on the binding rate.

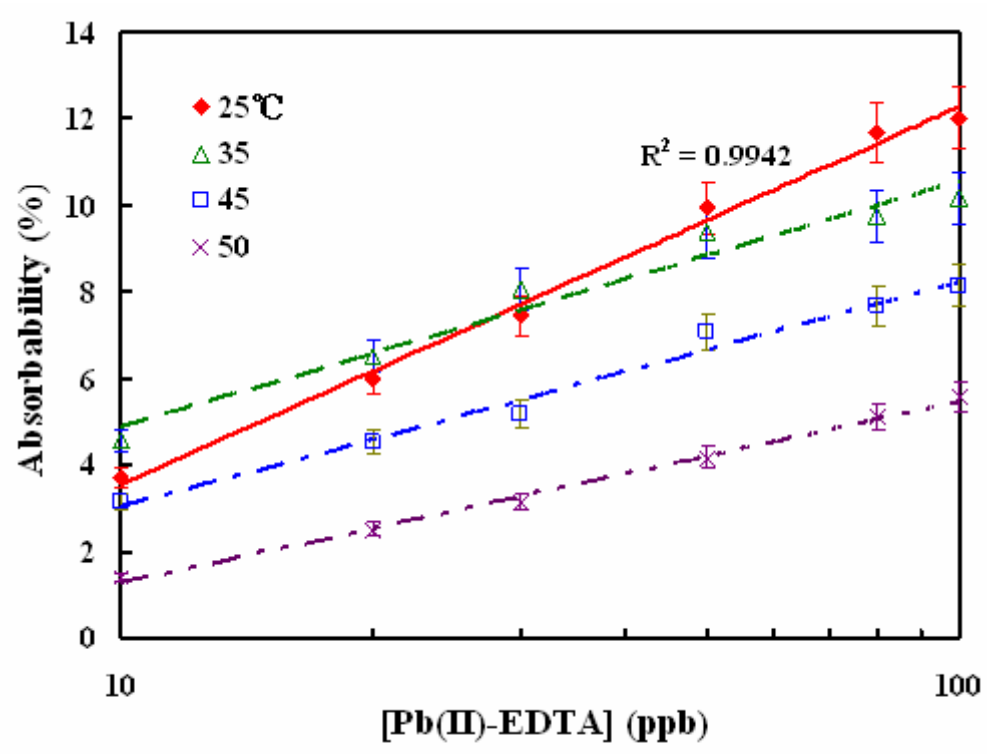

Figure 6. Effect of the detection temperature on the response for detecting 10 100 ppb $\mathrm{Pb}(\mathrm{II})$-EDTA complex in $\mathrm{pH} 7.4 \mathrm{PBS}$ buffer solution at $25^{\circ} \mathrm{C}$.

Another important issue on whether the monoclonal antibody-functionalized LSPR sensor is able to bind other metals needs to be addressed. Except Pb(II)-EDTA complex, the bindings of $\mathrm{Mg}$ (II)-, $\mathrm{Cu}(\mathrm{II})-$, and $\mathrm{Ni}$ (II)-EDTA complexes to the sensor were also examined, as shown in Fig. 7. Basically, the sensor shows a rather good linearity for the above metal ions. However, for $10 \sim 100 \mathrm{ppb}$ detecting 
range the absorbability of these three metal-EDTA complexes was only $3 \%$ change, which was smaller than that of $\mathrm{Pb}$ (II)-EDTA complex (12.2\%). That means the monoclonal antibody has a higher affinity to $\mathrm{Pb}(\mathrm{II})$-EDTA complex.

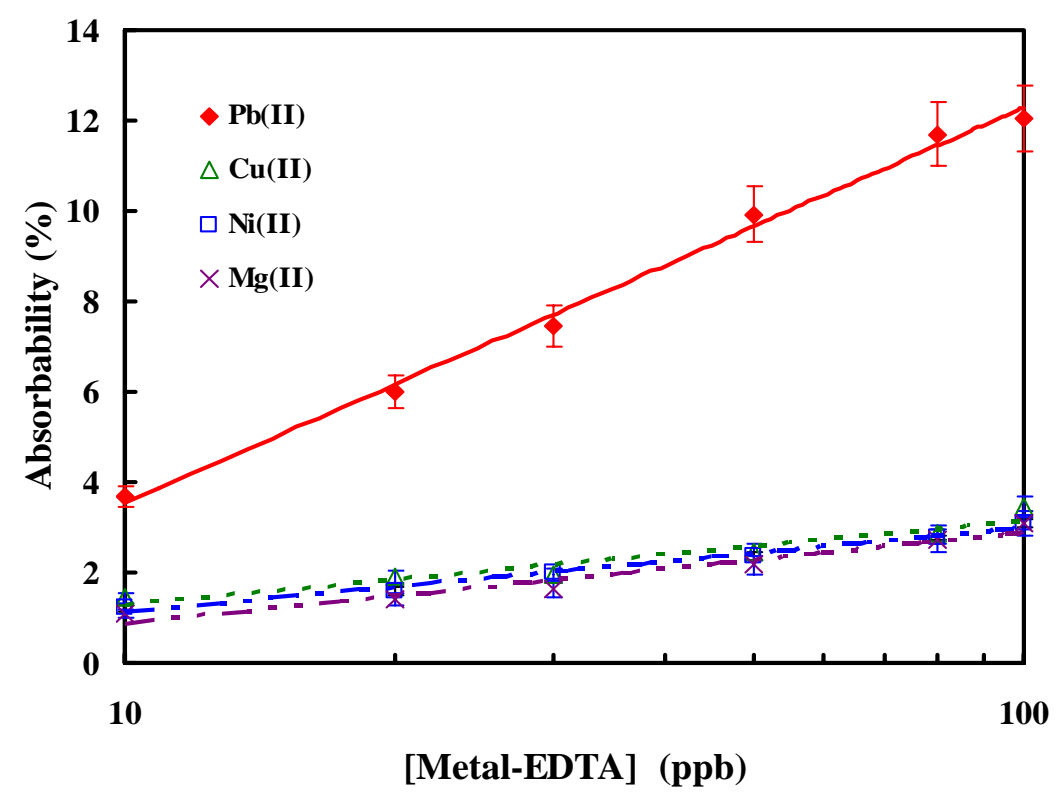

Figure 7. Comparison of the responses between different metal-chelate complexes (i.e., $\mathrm{Mg}(\mathrm{II})-, \mathrm{Cu}(\mathrm{II})-$, and Ni(II)-EDTA) through the monoclonal antibody-functionalized LSPR biosensor.

\subsection{Stability and dissociation constant}

Note that protein can cause structural folding and becomes denatured if the surface water on it is not conserved after a long-time storage. D-(+)-Trehalose dehydrate, known as mycose, is an alpha-linked sugar that has the merits of rehydration and anti-oxidation to perverse the activity of protein [25]. To prove the stability of our sensor, we performed the measurement of $\mathrm{Pb}$ (II)-EDTA complex using the sensors stored in $5 \% \mathrm{D}-(+)$-Trehalose dehydrate solution at $4{ }^{\circ} \mathrm{C}$ for up to 35 days after the initial measurement. The result shows that the relative activity of the sensor only decayed $7.2 \%$ after being stored for 35 days. Although there is some loss of the sensor activity after each cycle of use, the sensor can be recalibrated to determine $\mathrm{Pb}(\mathrm{II})$-EDTA complex concentration. There was no significant change in the calibration curve after 35-day storage.

\section{Conclusion}

A monoclonal antibody-functionalized LSPR biosensor bas been successfully developed for determining the concentration of $\mathrm{Pb}(\mathrm{II})$. The optimal incubating conditions for the immobilization of monoclonal antibody on to the LSPR biosensor were found to be $189 \mu \mathrm{g} / \mathrm{mL}$ monoclonal antibody in $\mathrm{pH}$ 7.4 PBS for $2 \mathrm{~h}$. With the optimal modification, the sensor can obtain a maximal $12.2 \%$ change of the absorbability for detecting 10 100 ppb Pb(II)-EDTA complex and a LOD of $0.27 \mathrm{ppb}$. The biosensor demonstrates a reproducible and stable response after over 35-day storage. Conclusively, 
the monoclonal antibody-modified LSPR biosensor can be used for the label-free detection of $\mathrm{Pb}$ (II)EDTA with an excellent sensitivity.

\section{Acknowledgements}

The work was supported by the National Science Council grant NSC-96-2214-E-194-035 in Taiwan.

\section{References and Notes}

1. Tong, S. Lead exposure and cognitive development: persistence and a dynamic pattern. J. Pediatr. Child Health 1998, 34, 114-118.

2. Lilienthal, H.; Winneke, G.; Ewert, T. Effects of lead on neurophysiological and performance measures: animal and human data. Environ Health Perspect. 1990, 89, 21-25.

3. CDC, Surveillance for elevated blood lead levels among children-United States, 1997-2001. Centers for Disease Control and Prevention MMWR Morb Mortal Wkly Rep. 2003, 53, 1-21.

4. Rothenberg, S.J.; Poblano, A.; Schnaas, L. Brainstem auditory evoked response at five years and prenatal and postnatal blood lead. Neurotoxicol Teratol. 2000, 22, 503-510.

5. Anderson, J.L.; Bowden, E.F.; Pickup, P.G. Dynamic electrochemistry: Methodology and application. Anal. Chem. 1996, 68, 379R-444R.

6. Burlingame, A.L.; Boyd, R.K.; Gaskell, S.J., Mass spectrometry. Anal. Chem. 1996, 599R-651R.

7. Jackson, K.W.; Chen, G. Atomic absorption, atomic emission, and flame emission spectrometry. Anal. Chem. 1996, 68, 231R-256R.

8. Zhyliak, G.A.; Dzyadevici, S.V.; Korpan, Y.I.; Soldatkin, A.P.; Elskaya, A.V. Application of urease conductometric biosensor for heavy metal ion determination. Sens. Actuat. B 1995, 24-25, 145-148.

9. Bontidean, I.; Ahlqvist, J.; Mulchandani, A.; Chen, W.; Bae, W.; Mehra, R.K.; Mortari, A.; Cso regi, E. Novel synthetic phytochelatin-based capacitive biosensor for heavy metal ion detection. Biosens. Bioelectron. 2003, 18, 547-553.

10. Bontidean, I.; Berggren, C.; Johansson, G.; Csoregi E.; Mattiasson, Bo; Lloyd, J.R.; Jakeman, K.J.; Brown, N.L. Detection of Heavy Metal Ions at Femtomolar Levels Using Protein-Based Biosensors. Anal. Chem. 1998, 70, 4162-4169.

11. Khosraviani, M.; Blake II, R.C.; Pavlov, A.R.; Lorbach, S.C.; Yu, H.; Delehanty, J.B.; Brechbiel, M.W.; Blake, D.A. Binding properties of a monoclonal antibody directed toward lead-chelate complexes. Bioconjugate Chem. 2000, 11, 267-277.

12. Blake, D.A.; Blake II, R.C.; Khosraviani, M.; Pavlov, A. R. Immunoassays for metal ions. Analytica Chimica Acta 1998, 376, 13-19.

13. Delehanty, J.B.; Jones, R.M.; Bishop, T.C.; Blake, D.A. Identification of Important Residues in Metal-Chelate Recognition by Monoclonal Antibodies. Biochemistry 2003, 42, 14173-14183.

14. Johnson, D.K.; Combes, S.H.; Parsen, J.; Jolley, A.A. Lead Analysis by Anti-Chelate Fluorescence Polarization Immunoassay. Environ. Sci. Technol. 2002, 36, 1042-1047. 
15. Chakrabarti, P; Hatcher, F.M.; Blake II, R.C.; Ladd, P.A.; Blake, D.A. Enzyme immunoassay to determine heavy metals using antibodies to specific metal-EDTA complexes: optimization and validation of an immunoassay for soluble indium. Anal. Biochem. 1994, 21, 70-75.

16. Reardan, D.T.; Meares, C.F.; Goodwin, D.A.; McTigue, M.; David, G.S.; Stone, M.R.; Leung, J.P.;Bartholomew, R.M.; Frincke, J.M. Antibodies against metal chelates. Nature 1985, 316, 265 268.

17. Blake II R.C.; J.B. Delehanty, M. Khosraviani, H. Yu, R.M. Jones, D.A. Blake, Allosteric Binding Properties of a Monoclonal Antibody and Its Fab Fragment. Biochemistry 2003, 497-508.

18. Lin, T.-J.; Huang, K.-T.; Liu, C.-Y. Determination of Organophosphorous Pesticides by a Novel Biosensor Based on Localized Surface Plasmon Resonance. Biosens. Bioelectron. 2006, 22, $513-$ 518.

19. Chau, L.-K.; Lin, Y.-F.; Cheng, S.-F.; Lin, T.-J. Fiber-optic chemical and biochemical probes based on localized surface plasmon resonance. Sens. Actuat. B 2006,113, 100-105.

20. Jensen, T.R.; Duval, M.; Kelly, K.L.; Lazarides, A.A.; Schatz, G.C.; Richard, P.Van D. Nanosphere lithography: Effect of the external dielectric medium on the surface plasmon resonance spectrum of a periodic array of silver nanoparticles. J. Phys. Chem. B 1999, 103, 98469853.

21. Nath, N.; Chilkoti, A. A colorimetric gold nanoparticle sensor to interrogate biomolecular interactions in real time on a surface. Anal Chem. 2002, 74, 504-509.

22. Haes, A.J.; van Duyne, R.P. A nanoscale optical biosensor: sensitivity and electivity of an approach based on the localized surface plasmon resonance spectroscopy of triangular silver nanoparticles. J. Am. Chem. Soc. 2002, 124, 10596-10604.

23. Jorgenson, R.C.; Yee, S.S. A fiber-optic chemical sensor based on surface plasmon resonance, Sens. Actuat. B 1993, 12, 213-218.

24. Gestwicki, J.E.; Cairo, C.W.; Mann, D.A.; Owen, R.M.; Kiessling, L.L. Selective Immobilization of Multivalent Ligands for Surface Plasmon Resonance and Fluorescence Microscopy. Anal Chem. 2002, 305, 149-155.

25. Higashiyama, T. Novel functions and applications of trehalose. Pure Appl. Chem. 2002, 74, 12631269.

(C) 2008 by MDPI (http://www.mdpi.org). Reproduction is permitted for non commercial purpose 